\title{
TIPOS DE HOMICÍDIO E FORMAS DE PROCESSAMENTO: EXISTE RELAÇÃO?'
}

\section{Ludmila Mendonça Lopes Ribeiro²}

Vinícius Assis Couto ${ }^{3}$

Resumo: A (in)capacidade do sistema de justiça criminal em responder adequadamente o número alarmante de homicídios é um tema recorrente em jornais e revistas especializadas. Nessas publicações, o tempo que transcorre entre o crime e a sua apreciação final pelo Judiciário, bem como a sentença final, são apontados como medidas da capacidade do sistema em responsabilizar os criminosos. Este artigo problematiza em que medida o desfecho final e o tempo de processamento são produtos de uma tipologia de homicídio, a partir da análise das informações coletadas em 205 processos arquivados em 2013 na cidade de Belo Horizonte.

Palavras-chave: Sistema de justiça; tempo de processamento; sentenciamento; análise de sobrevivência.

\section{TYPE OF HOMICIDE AND TRIAL LENGTH: IS THERE A RELATIONSHIP?}

1 Trabalho resultante da pesquisa "Tempo médio do processo de homicídio doloso", financiada pela parceria estabelecida por meio de carta de acordo firmada entre a Secretaria de Reforma do Judiciário, o Programa das Nações Unidas para o Desenvolvimento e a Fundação de Desenvolvimento da Pesquisa - FUNDEP. Uma primeira versão deste artigo foi apresentada no XVII Encontro da Sociedade Brasileira de Sociologia, realizado em 2015, na cidade de Porto Alegre. Agradecemos os comentários do Professor Rodrigo Azevedo, debatedor da sessão, que contribuíram para a versão final deste trabalho.

2 Departamento de Sociologia da Universidade Federal de Minas Gerais (UFMG) - Centro de Estudos de Criminalidade e Segurança Pública - Belo Horizonte - Brasil - ludmila.ribeiro@gmail.com

3 Doutorando pelo Departamento de Sociologia da Universidade Federal de Minas Gerais (UFMG) - Centro de Estudos de Criminalidade e Segurança Pública - Belo Horizonte - Brasil - viniccouto@gmail.com 
Abstract: The (in)ability of the criminal justice system to respond to the dangerous number of homicides is an important theme in newspapers and specialized magazines. In those publications, the length of time between the crime and its final handling by the judiciary, as well as the final verdict, are understood as measures of the system's ability to charge criminals. In this paper, we argue that the final sentence and the length of time of trials are products of a homicide typology. For this purpose, we use the information gathered in 205 proceedings finished (archived) in 2013 in the city of Belo Horizonte.

Keywords: Justice system; length of time; sentencing; survival analysis.

\section{Introduç̣̃o}

Em um artigo publicado no ano de 2000, intitulado Homicídios no Brasil: vários factoides em busca de uma explicação, Gláucio Soares chamava a atenção para a forte correlação entre gênero, idade, estado civil, porte de arma de fogo e mortes violentas. Segundo o autor, uma crescente literatura sobre o tema seria capaz de explicar o crescimento do fenômeno na América Latina, mas, em razão do não teste desses constructos, terminávamos com "teorias sem dados", ao mesmo tempo em que se multiplicavam os "dados em busca de uma teoria" (SOARES, 2000: 43). Em última instância, sendo conhecido o perfil do autor, seria possível predizer o perfil da vítima e vice-versa, o que reforçava a ideia de que a dinâmica de mortes violentas é, em verdade, a expressão de um padrão de sociabilidade típico das metrópoles brasileiras.

Nas pesquisas sobre fluxo do sistema de justiça criminal, a situação não parece ser diferente. Conforme apontado por Joana Vargas (2014: 411), há uma crescente produção nacional preocupada em descrever "as práticas de construção social e institucional do crime e sua representação, em números e taxas, produzida com base no resultado dos processos decisórios sequenciais que se dão na polícia, na justiça e na execução penal". Na revisão produzida pela autora, é citada mais de uma dezena de estudos que se preocupam em entender os percursos dos documentos que sumarizam os crimes, criminosos e vítimas desde a constatação da ocorrência do delito por uma agência oficial de controle até a sentença de condenação ou absolvição, mas sem uma preocupação em entender a fundo os determinantes desses padrões decisórios.

As análises sobre padrão de processamento e sentenciamento procuram acompanhar as respostas institucionais dadas a crimes graves, como os homicídios intencionais, os estupros e os roubos. Os factoides decorrentes dessas investigações são relativamente os mesmos e apontam para a facilidade de se identificar um suspeito quando ele apresenta características que possibilitam 
rotulá-lo previamente como um "bandido". Assim, homens jovens, pretos ou pardos, e residentes de periferia teriam mais chances de serem acusados, processados e punidos pelo sistema de justiça criminal do que outros indivíduos. A estigmatização funcionaria "como uma profecia que se autocumpre" em razão dos padrões de "seleção e filtragem a que essas pessoas são submetidas" (VARGAS, 2014: 415). São também esses os processos que tramitam mais rapidamente entre as agências que compõem o sistema, frouxamente articulado, de segurança pública e justiça criminal.

A proposta deste trabalho é contribuir com essa discussão introduzindo um elemento que parece ter sido negligenciado pela literatura especializada nos últimos anos: as explicações apontadas pelos operadores do sistema de justiça criminal como causa da morte violenta. A hipótese que se pretende testar é a de que o tempo de processamento e o desfecho do processo tendem a ser distintos de acordo com a dinâmica do delito.

A ideia subjacente a essa hipótese é a de que a responsabilização dos crimes que violam dinâmicas de sociabilidade estruturantes da vida em sociedade - como a vida em família e as amizades - tende a ser mais branda quando comparada a delitos decorrentes de uma atividade comercial, como é o caso dos relacionados ao tráfico de drogas, por ser essa a explicação comumente apontada para o aumento substantivo das mortes violentas no Brasil (SAPORI et al, 2010).

Mais especificamente, o objetivo deste trabalho é retomar essa discussão a partir da criação de uma tipologia de homicídios que leva em consideração as razões apresentadas pelos operadores do sistema de justiça criminal para a morte violenta. Para tanto, será utilizado o material coletado na consulta a 205 processos penais de competência do Tribunal do Júri, baixados em 2013, na cidade de Belo Horizonte.

\section{Tipologia de homicídios}

Tomando como ponto de partida uma perspectiva microssociológica, é possível afirmar que a vida em sociedade é repleta de categorizações. Para que as interações sociais aconteçam com um mínimo de previsibilidade, os indivíduos tendem a organizar as situações com as quais se defrontam cotidianamente dentro de certas categorias. Por isso, dizemos que a sociedade não existe de uma forma objetiva, e, sim, de maneira altamente subjetiva, por decorrer da forma como a construímos, como a interpretamos, e do modo como agimos sobre ela (BERGER; LUCKMANN, 1991).

A criação de categorias para a compreensão de determinados fenômenos sociais é, portanto, uma atividade que estrutura o saber sociológico. No caso das mortes violentas, alguns estudos chamam a atenção para como saberes médicos (SUDNOW, 1971) e jurídicos (SILVA, 2010) são acionados para a classificação do 
evento em termos de sua intencionalidade: se homicídio, suicídio ou acidente. Para tanto, são considerados elementos presentes no próprio cadáver, além da trajetória de vida do morto e das narrativas constituídas por pessoas próximas e especialistas no tema - como peritos advogados e médicos - com o objetivo de "descobrir, reconhecer, denominar e tratar a morte" dentro de um mundo social organizado (SUDNOW, 1971: 22). É a partir da reunião de uma série de informações sobre o evento social "morte" que especialistas tornam viável a sua interpretação e, por conseguinte, a sua classificação dentro de sistemas sociais (como o sistema de saúde e o jurídico).

A preocupação com a classificação da morte segundo a sua intencionalidade diz respeito, entre outras dimensões, ao tipo de resposta estatal que será acionada em relação àquele corpo sem vida. Na última edição do estudo global de homicídios, o UNODC (2014: 41) destacou a necessidade de se compreender por que os indivíduos ceifam de maneira proposital a vida uns dos outros para que esse saber se transforme em estratégias e políticas públicas de prevenção e redução da violência letal e intencional. $\mathrm{O}$ documento apresenta uma primeira tipologia de mortes violentas intencionais, estruturada a partir de três classes fundamentais: interpessoal, relacionada a atividades criminais e sociopolíticas (Figura 1).

Figura 1 - Tipologia de mortes violentas intencionais proposta pelo UNODC (2014)

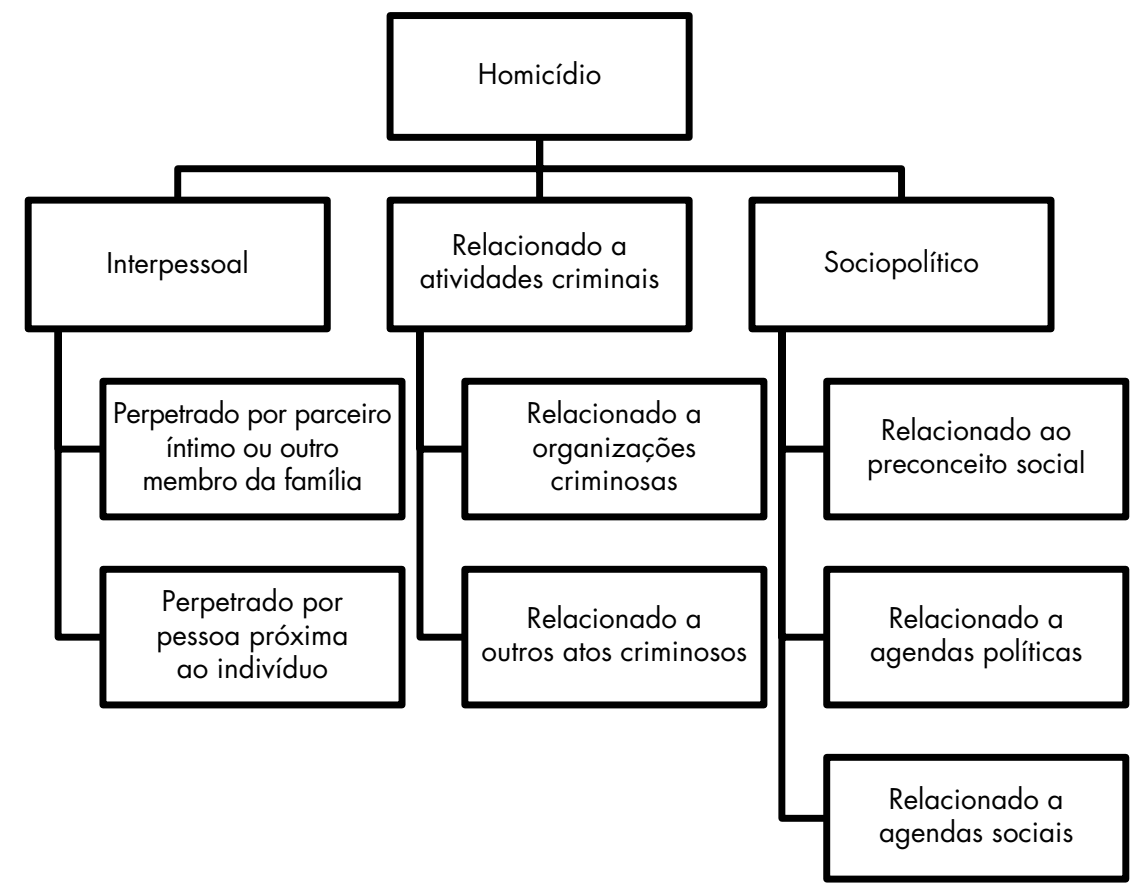


A primeira categoria diz respeito ao homicídio intencional como um mecanismo de resolução de conflitos dentro de relações de sociabilidade previamente existentes. Dentro dela existem duas categorias, tendo como referente a relação íntima com a família, que é entendida como distinta de outros relacionamentos interpessoais em razão do "nível de apego emocional e outros links, muitas vezes de natureza econômica ou legal, entre a vítima e o agressor" (UNODC, 2014: 42). A resultante de relações de proximidade, isto é, amigos, vizinhos e conhecidos é aquela em que, em razão de uma controvérsia qualquer, os indivíduos terminam por resolvê-la de forma violenta.

A segunda classe inclui as mortes violentas intencionais que acontecem como meio para alcançar outra finalidade criminal, como a garantia direta ou indireta de lucros ilícitos. Nessa situação se incluem "os homicídios que não representam o principal objetivo da maioria dos criminosos, embora possam ser perpetrados a fim de viabilizar o crime original e/ ou evitar a detecção" (UNODC, 2014: 40). A forma de distinção das categorias é: se o homicídio é utilizado para a garantia da operação de determinados grupos criminosos ao longo do tempo (na qual se inseririam os delitos decorrentes da disputa por território no tráfico de drogas, típica de algumas periferias brasileiras) e ou se é apenas uma externalidade da atividade ilegal, categoria que englobaria os latrocínios, os homicídios decorrentes da tentativa de manter a propriedade de um bem roubado.

A terceira e última categoria de mortes violentas diz respeito aos homicídios intencionais que têm motivação social ou política. Nela são classificados os casos de "pessoas que são mortas pelo que representam e/ou pela mensagem que tais assassinatos podem transmitir ao público em geral ou para subsectores específicos" (UNODC, 2014: 41). Apesar de essas mortes não serem muito comuns no Brasil, é crescente a quantidade de casos de autos de resistência. Essas são as situações em que a polícia mata, muitas vezes, de forma intencional, já que a justiça não consegue punir adequadamente esses casos (MISSE, 2011). Se pressupomos que a polícia é um agente do Estado, então, as suas ações trazem um fim político, o que faz com as mortes ocasionadas por essa instituição sejam contempladas em um novo tipo. Também podem ser considerados homicídios intencionais sociopolíticos os linchamentos, que são uma forma de demonstrar a insatisfação com o padrão de operação do sistema de justiça a partir da aplicação de punições com as próprias mãos (MARTINS, 2015).

A categorização apresentada pelo UNODC (2014) pode ser tomada como ponto de partida para análise dos casos de homicídio doloso cujo processamento penal foi encerrado pelo Tribunal do Júri de Belo Horizonte no ano de 2013. Esse material compreende apenas os homicídios formalmente enquadrados 
como dolosos, i.e., aqueles em que houve a intenção de matar. No entanto, para criar tipos de mortes violentas intencionais, delegados de polícia, promotores de justiça, defensores públicos e juízes muitas vezes se utilizam de duas dimensões, para além das balizas estabelecidas pelo Art. 121 do Código Penal: os fatores estruturais, que "dizem respeito ao contexto em que os crimes ocorreram (território ou local, horário, instrumento utilizado pelo agressor, dentre outros)" e os fatores individuais, que "abarcam as características sociodemográficas dos envolvidos e a relação social entre vítimas e agressores" (SILVA, 2013: 43).

Acrescentamos os fatores individuais e estruturais na classificação do UNODC para que essa tipologia leve em consideração a relação social entre os envolvidos, a territorialidade (importante em crimes relacionados ao tráfico de drogas) e, ainda, o motivo pelo qual o óbito aconteceu. Essas seriam as dimensões que qualificariam os diversos tipos de homicídios interpessoais, relacionados a atividades criminosas e decorrentes de questões sociopolíticas.

Nesse exercício, além de desagregar as categorias anteriores (Figura 1), em diversas outras (Figura 2), ampliando o espectro para a classificação das mortes violentas intencionais, foi acrescentada uma quarta classe: a relacionada aos casos mal definidos, aqueles em que as autoridades com poder de classificar uma determinada morte não apontam qualquer justificativa substantiva para a sua ocorrência, resumindo-se a relatar o óbito como vingança (sem qualificar o motivo desse), ou se limitando a dizer que a violência letal aconteceu e quando foi praticada.

Figura 2 - Tipologia dos homicídios intencionais revista

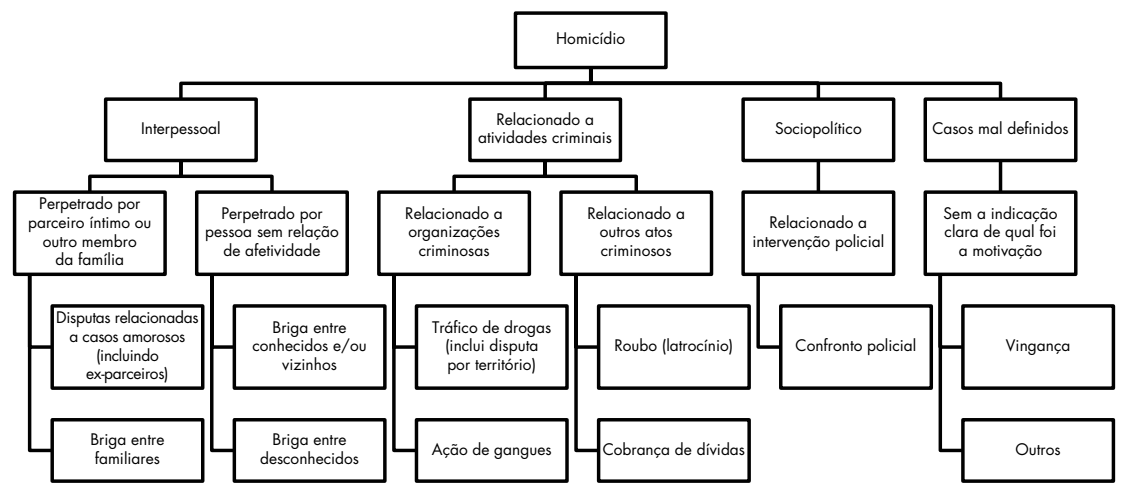

Fonte: Revisão de UNODC (2014)

Neste estudo, pretendemos testar se a tipologia de homicídios intencionais produz o efeito esperado, isto é, condiciona a interação dos operadores do sistema de justiça criminal, fazendo com que esses casos tenham perfis semelhantes em 
termos de tempo de processamento e das sentenças recebidas. Esse efeito da tipificação é esperado em razão do entendimento de que os indivíduos, ao categorizarem situações, constroem "teorias de senso comum (as expectativas de background que todos utilizamos) (...) que vão constituir o quadro de referência a partir do qual o mundo deve ser interpretado para a solução de problemas práticos à mão" (SILVA, 2013: 50). Espera-se, então, que tipos iguais de mortes violentas tenham padrões de processamento semelhantes, o que aumentaria o entendimento dos determinantes da seleção e filtragem, bem como dos condicionantes da lentidão da justiça.

\section{0 fluxo de processamento em Belo Horizonte a partir dos tipos de homicídio}

O material empírico utilizado para a elaboração deste estudo foi um conjunto de 205 processos penais baixados (isto é, remetidos ao arquivo) na cidade de Belo Horizonte, o que representa $40 \%$ do volume total de baixas processuais naquele ano. ${ }^{4}$ Os autos processuais foram considerados como fonte de informação por reunirem uma farta documentação, que permite a reconstituição do delito e da trajetória do criminoso e da vítima, a partir das narrativas apresentadas pelos representantes das instituições que compõem o sistema de segurança pública e justiça criminal no Brasil. A proposta desta seção é descortinar como "o processo de produção da verdade que transfigura atos em autos; promove embates entre acusadores e acusados, com vistas a punir, graduar a pena ou absolver" (ADORNO, 2001: 12).

De acordo com arcabouço institucional estabelecido pela Constituição da República Federal Brasileira (CRFB/1988), cabe à Polícia Militar o patrulhamento ostensivo. Ao responder as chamadas ao 190, patrulhar a cidade ou ser acionada por Guardas Municipais, os policiais militares identificariam as mortes violentas e as documentariam em um Registro de Ocorrências (RO). Caber-lhes-ia, em seguida, encaminhar o material reunido (na maior parte das vezes, papéis sobre o crime) para as delegacias de polícia. Em 192, dos 205 processos de homicídio doloso analisados, o RO da Polícia Militar estava adequadamente anexado aos autos, indicando quando o delito ocorreu e, em algumas situações, apontando motivos para a sua prática. Em 13 casos, outros órgãos do sistema de segurança pública foram diretamente acionados para o registro inicial do evento e o documento da polícia ostensiva não compunha o acervo documental desta fase.

4 De acordo com as informações coletadas junto ao Tribunal de Justiça de Minas Gerais, no ano de 2013 foram arquivados 988 inquéritos policiais, referentes a delitos, cuja autoria não pôde ser apontada, e 560 processos, incluídos nessa categoria os crimes denunciados pelo Ministério Público perpassados por algum tipo de apreciação judicial. 
Ao receber as informações dos policiais militares, de outros órgãos ou cidadãos, os delegados devem tomar as providências relativas à atividade de investigação, com o objetivo de apontar um suspeito para o crime. Assim, a abertura do Inquérito Policial significa a reunião de documentos que permitem qualificar o evento descrito no Código Penal. ${ }^{5}$ Nos processos em análise foram mobilizados procedimentos que buscam reconstruir o delito, tais como a oitiva de testemunhas de fato (presente em 133 dos 205 casos), a oitiva de testemunhas de caráter (188 casos), as perícias (192 casos) e, até mesmo, a confissão do suspeito (19 casos). Quando encerrado, o Inquérito Policial foi encaminhado ao Judiciário e, dele, ao Ministério Público, para o oferecimento da denúncia. ${ }^{6} \mathrm{Na}$ maioria das vezes, o promotor de justiça se limitou a repetir a interpretação dada pelo delegado de polícia em seu relatório final, mas nem por isso o papel desse documento foi de menor importância (SILVA, 2010). Afinal, é a denúncia que torna o indivíduo formalmente acusado da prática de um determinado delito, abrindo-lhe a possibilidade de apresentar a sua defesa, sendo este o início do processo judicial.

Partindo da denúncia como fonte para o enquadramento dos processos pesquisados na tipologia apresentada na Figura 2, constata-se que a maioria diz respeito à classe interpessoal ( 125 casos), seguida de casos relacionados a atividades criminais (56 casos) e uma reduzida participação dos casos de natureza sociopolítica ( 5 casos). 19 casos foram mal enquadrados, o que impediu a sua inclusão nas classes anteriormente mencionadas (Tabela 1).

Tabela 1 - Distribuição dos homicídios dolosos analisados, segundo a tipologia construída a partir da denúncia - processos de homicídio doloso baixados em Belo Horizonte em 2013

\begin{tabular}{|l|l|l|c|c|}
\hline Macrocategoria & \multicolumn{1}{|c|}{ Classe } & \multicolumn{1}{|c|}{ Tipo } & N. & \multicolumn{1}{c|}{$\%$} \\
\hline \multirow{5}{*}{ Interpessoal } & Conflito familiar & $\begin{array}{l}\text { Disputas relacionadas } \\
\text { a casos amorosos } \\
\text { (incluindo ex-parceiros) }\end{array}$ & 35 & $17 \%$ \\
\cline { 3 - 6 } & & Briga entre familiares & 13 & $6 \%$ \\
\cline { 2 - 6 } & $\begin{array}{l}\text { Conflito perpetrado por pessoa } \\
\text { sem relação de afetividade }\end{array}$ & $\begin{array}{l}\text { Briga entre conhecidos/ } \\
\text { vizinhos }\end{array}$ & 53 & $26 \%$ \\
\cline { 3 - 7 } & $\begin{array}{l}\text { Briga entre desconhe- } \\
\text { cidos }\end{array}$ & 24 & $12 \%$ \\
\hline
\end{tabular}

(continua)

$5 \mathrm{CPP}$, Art. $9^{\circ}$ Todas as peças do inquérito policial serão, num só processado, reduzidas a escrito ou datilografadas e, neste caso, rubricadas pela autoridade.

$6 \mathrm{CPP}, \operatorname{Art} .12^{\circ} \mathrm{O}$ inquérito policial acompanhará a denúncia ou queixa, sempre que servir de base a uma ou outra. 


\begin{tabular}{|c|c|c|c|c|}
\hline \multirow{4}{*}{$\begin{array}{l}\text { Relacionado a } \\
\text { atividades } \\
\text { Criminais }\end{array}$} & \multirow{2}{*}{$\begin{array}{l}\text { Relacionado a organizações } \\
\text { criminosas }\end{array}$} & Ação de gangues & 7 & $3 \%$ \\
\hline & & Tráfico de drogas & 38 & $19 \%$ \\
\hline & \multirow{2}{*}{$\begin{array}{l}\text { Relacionado a outros atos } \\
\text { criminosos }\end{array}$} & Roubo (latrocínio) & 3 & $1 \%$ \\
\hline & & Cobrança de dívidas & 8 & $4 \%$ \\
\hline Sociopolítico & $\begin{array}{l}\text { Relacionado a intervenção } \\
\text { policial }\end{array}$ & Confronto policial & 5 & $2 \%$ \\
\hline \multirow{2}{*}{ Mal definidas } & \multirow{2}{*}{$\begin{array}{l}\text { Sem a indicação clara de qual } \\
\text { foi a motivação }\end{array}$} & Vingança & 13 & $6 \%$ \\
\hline & & Outros & 6 & $3 \%$ \\
\hline Total & & & 205 & $100 \%$ \\
\hline
\end{tabular}

Fonte: Mensurando o tempo do processo de homicídio em cinco capitais (CRISP/ UFMG)

Após receber a denúncia, o juiz deu ciência ao indiciado de sua acusação formal e, dessa forma, abriu-lhe prazo para exercício do direito de ampla defesa, o que em 90 casos (dos 205 casos) foi assegurado a partir da nomeação de um defensor público ou advogado (nesse caso, escolhido pelo próprio acusado). ${ }^{7}$ Com a nomeação do defensor, o acusado começou a responder às imputações que lhe eram feitas quanto à prática do delito, podendo arrolar testemunhas (no máximo de oito) a serem ouvidas na Audiência de Instrução de Julgamento (AIJ).

$\mathrm{Na}$ AIJ foram ouvidas testemunhas do fato (98 casos), testemunhas de caráter (170 casos) e alguns peritos (17 casos), de forma a validar os indícios coletados na polícia e, assim, transformá-los em provas. Em 82 casos, o acusado confessou a prática do delito, assumindo a responsabilidade pela morte de alguém. Em seguida, o promotor de justiça e o defensor se enfrentaram em um debate, com vistas a estabelecer a narrativa mais consistente sobre o crime. A sentença nesta fase foi de quatro tipos: absolvição, quando os fatos apresentados demonstraram que não houve crime e/ou o sujeito incriminado não foi o responsável pelo delito (cinco casos); desclassificação, quando se constatou que o homicídio não foi praticado de forma dolosa, devendo o seu julgamento ser efetuado pelo juiz singular, e não pelo júri (sete casos); impronúncia, quando o juiz entendeu que as provas apresentadas não eram suficientes, devendo o processo aguardar até que novos indícios de autoria e materialidade do delito fossem apresentados (41 casos); pronúncia, que consistiu na chancela do julgamento

7 CPP, Art. 406. O juiz, ao receber a denúncia ou a queixa, ordenará a citação do acusado para responder a acusação, por escrito, no prazo de 10 (dez) dias. 
pelo júri, por se tratar de um crime doloso contra a vida (151 casos). ${ }^{8}$ Em uma situação, o processo foi extinto em razão da morte do acusado.

Desagregando os desfechos da AIJ por tipo de homicídio, tem-se que os acusados por tráfico de drogas foram os mais susceptíveis à impronúncia, seguido dos acusados por conflitos amorosos em geral, independentemente do marcador de gênero (Tabela 2). No entanto, não existem diferenças estatisticamente significativas entre a natureza do desfecho dessa fase e os tipos de homicídios, como indica o teste do qui-quadrado. ${ }^{9}$

Tabela 2 - Distribuição dos desfechos da AIJ, de acordo com a tipologia de homicídios - processos de homicídio doloso baixados em Belo Horizonte em 2013

\begin{tabular}{|c|c|c|c|c|c|c|c|}
\hline & & \multicolumn{5}{|c|}{ Qual a decisão da AIJ? } & \multirow{2}{*}{ Tota } \\
\hline & & Pronúncia & Impronúncia & Desclassificação & Absolvição & Extinção & \\
\hline \multirow[t]{11}{*}{ Tipologia } & $\begin{array}{l}\text { Disputas relacionadas a } \\
\text { casos amorosos (incluin- } \\
\text { do ex-parceiros) }\end{array}$ & 24 & 8 & 2 & 1 & 0 & 35 \\
\hline & Briga entre familiares & 11 & 0 & 1 & 1 & 0 & 13 \\
\hline & $\begin{array}{l}\text { Briga entre conhecidos/ } \\
\text { vizinhos }\end{array}$ & 45 & 4 & 2 & 2 & 0 & 53 \\
\hline & Briga entre desconhecidos & 22 & 1 & o & o & 1 & 24 \\
\hline & Ação de gangues & 2 & 5 & 0 & 0 & 0 & 7 \\
\hline & Tráfico de drogas & 20 & 15 & 2 & 1 & 0 & 38 \\
\hline & Roubo (latrocínio) & 3 & o & 0 & 0 & 0 & 3 \\
\hline & Cobrança de dívidas & 7 & 1 & 0 & 0 & o & 8 \\
\hline & Confronto policial & 4 & 1 & 0 & o & 0 & 5 \\
\hline & Vingança & 8 & 5 & 0 & o & o & 13 \\
\hline & Outros & 5 & 1 & 0 & o & 0 & 6 \\
\hline Total & & 151 & 41 & 7 & 5 & 1 & 205 \\
\hline
\end{tabular}

Fonte: Mensurando o tempo do processo de homicídio em cinco capitais (CRISP/ UFMG)

Quando a decisão de pronúncia não pôde mais ser contestada (ou seja, discutida em recursos), teve início a segunda fase do procedimento do júri. Inicialmente, o juiz intimou o promotor de justiça para que ele apresentasse uma lista de testemunhas e peritos a serem ouvidos em plenário. Após o recebimento dessas informações, o magistrado abriu vistas do processo para a defesa, para

8 CPP, Art. 413. O juiz, fundamentadamente, pronunciará o acusado, se convencido da materialidade do fato e da existência de indícios suficientes de autoria ou de participação.

9 O teste qui-quadrado mede a independência de variáveis para verificar se há associação entre essas duas informações. No entanto, não se pode estabelecer uma relação de causalidade, já que esse não é um teste apropriado. Ou seja, pode-se afirmar que os fenômenos estão relacionados, mas não que um causa o outro necessariamente. 
que ela apresentasse a sua lista de testemunhas e peritos. ${ }^{10}$ Por último, coube ao juiz preparar um relatório final de todos os incidentes ocorridos no curso da ação penal, a ser disponibilizado aos jurados no dia do júri.

Após a instalação da sessão do júri, foram ouvidas as testemunhas do fato ou de caráter (65 de 151 casos pronunciados) e os peritos (48 casos), além do próprio acusado, que confessou o crime em 55 casos. Encerrados os depoimentos, foi realizada a sustentação oral do promotor, que deveria incriminar o acusado mencionando os termos da decisão de pronúncia, as provas constantes no processo e, ainda, os depoimentos das testemunhas ouvidas em plenária (se for o caso). Ocorre que, em razão da função do membro do MP ser também a promoção da justiça, e não apenas a acusação penal, em 24 casos dos 151 pronunciados, ele pediu a absolvição do réu por ausência de provas. Essa situação aconteceu, com maior frequência, em casos que envolviam brigas entre vizinhos e pessoas conhecidas (7 casos) ou tráfico de drogas (6 casos), como indica o Gráfico 1.

Gráfico 1 - Distribuição das situações em que o Ministério Público solicitou a absolvição do acusado - processos de homicídio doloso baixados em Belo Horizonte em 2013

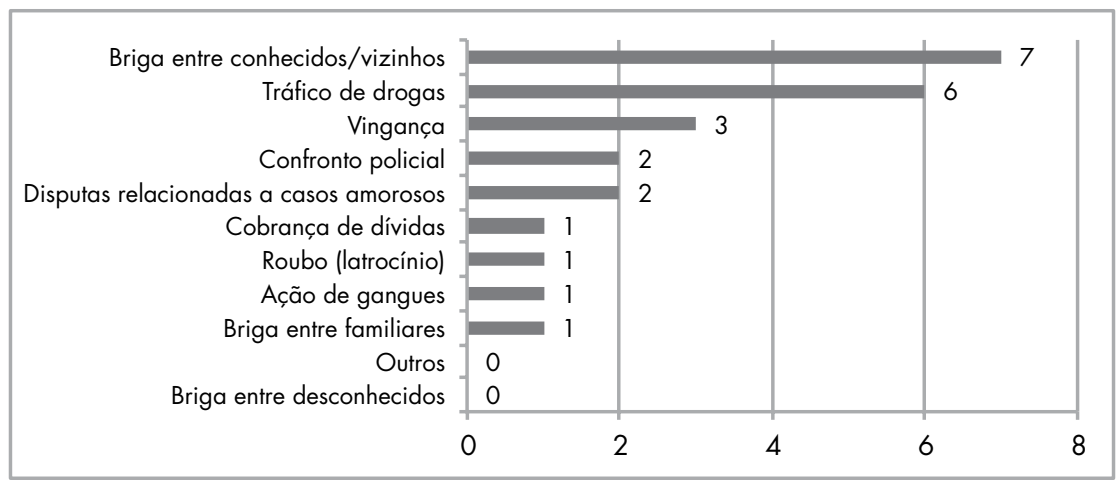

Fonte: Mensurando o tempo do processo de homicídio em cinco capitais (CRISP/ UFMG)

Depois do promotor, foi a vez do defensor apresentar suas teses em plenário. Após essa fala, promotores e defensores tiveram direito à réplica e à tréplica. Encerradas as sustentações orais, o juiz perguntou aos jurados se eles estavam prontos para julgar. Sendo afirmativo, o juiz presidente leu os quesitos, que são perguntas sobre a materialidade (se houve crime), a autoria (se foi o réu que

10 CPP, Art. 422. Ao receber os autos, o presidente do Tribunal do Júri determinará a intimação do órgão do Ministério Público ou do querelante, no caso de queixa, e do defensor, para, no prazo de 5 (cinco) dias, apresentarem rol de testemunhas que irão depor em plenário, até o máximo de 5 (cinco), oportunidade em que poderão juntar documentos e requerer diligência. 
cometeu o crime), a absolvição do réu, as causas de diminuição de pena (alegadas pela defesa) e a qualificação do delito (alegadas pela acusação). A cada uma dessas perguntas, os jurados devem responder depositando uma cédula do tipo "sim" ou "não" na urna de votação. Isso porque, no Brasil, os jurados não discutem o veredito (como ocorre nos EUA), mas devem se manter incomunicáveis, sob pena de o julgamento ser considerado nulo. Assim, o julgamento se estabelece a partir da maioria de votos, de maneira que quesitos vencidos por quatro votos "sim" e três "não" têm o mesmo peso que os quesitos vencidos por sete votos sim (ou não).

Três foram as decisões nessa etapa: absolvição (78 casos), condenação (41 casos) e desclassificação (32 casos), que aconteceu quando os jurados entenderam que o réu não praticou homicídio doloso, mas culposo, e, por isso, não cabia ao conselho de sentença decidir individualmente o seu destino, mas sim ao juiz presidente. Desagregando as decisões pelos tipos de homicídio, constata-se que as categorias com maior quantitativo de condenações foram as relativas aos conflitos interpessoais, com destaque para aquelas que se referem a brigas entre conhecidos e vizinhos e as brigas entre pessoas com algum tipo de vínculo amoroso (Tabela 3). Novamente, não existe significância estatística entre as categorias de homicídio e o desfecho desta fase, de acordo com o teste do qui-quadrado.

Tabela 3 - Distribuição da decisão do júri segundo a tipologia de homicídios - processos de homicídio doloso baixados em Belo Horizonte em 2013

\begin{tabular}{|c|c|c|c|c|c|}
\hline & & \multicolumn{3}{|c|}{ Qual foi a sentença recebida pelo réu? } & \multirow{2}{*}{ Total } \\
\hline & & Absolvição & Condenação & Desclassificação & \\
\hline \multirow[t]{11}{*}{ tipologia } & $\begin{array}{l}\text { Disputas relacionadas a casos } \\
\text { amorosos (incluindo ex-parceiros) }\end{array}$ & 9 & 6 & 6 & 21 \\
\hline & Briga entre familiares & 3 & 5 & 2 & 10 \\
\hline & Briga entre conhecidos/vizinhos & 19 & 16 & 11 & 46 \\
\hline & Briga entre desconhecidos & 8 & 5 & 5 & 18 \\
\hline & Ação de gangues & 4 & o & 1 & 5 \\
\hline & Tráfico de drogas & 14 & 4 & 4 & 22 \\
\hline & Roubo (latrocínio) & 1 & o & 1 & 2 \\
\hline & Cobrança de dívidas & 5 & 2 & 1 & 8 \\
\hline & Confronto policial & 4 & 1 & 0 & 5 \\
\hline & Vingança & 9 & 1 & 0 & 10 \\
\hline & Outros & 2 & 1 & 1 & 4 \\
\hline Total & & 78 & 41 & 32 & 151 \\
\hline
\end{tabular}

Qui-quadrado $=19,68(0,478)$

Fonte: Mensurando o tempo do processo de homicídio em cinco capitais (CRISP/ UFMG) 
Outra forma de se apresentar o fluxo do sistema de justiça criminal é quantificando os papéis (VARGAS, 2014), que se referem aos boletins de ocorrência (na polícia militar), aos inquéritos policiais (na polícia civil), às denúncias (no Ministério Público) e às sentenças de condenação (no Judiciário). Como os autos processuais condensam uma série de documentos, produzidos por diversas organizações ao longo de determinados períodos de tempo, a absolvição ou a condenação de um suspeito depende da forma como esses documentos foram produzidos e dos caminhos que lograram (ou não) percorrer. Dos 205 processos que foram objeto de análise detalhada, $26 \%$ foram encerrados na fase de pronúncia e, dos pronunciados (151 casos), 27\% (41 casos) alcançaram a condenação.

Utilizando a denúncia como documento base de classificação dos tipos de homicídio doloso, verifica-se a força das categorias como preditoras de padrões de seleção e filtragem (Tabela 4). As mortes decorrentes de brigas entre vizinhos e brigas entre conhecidos e familiares têm uma participação percentual maior no montante de condenações do que no montante de denúncias, enquanto o homicídio intencional no tráfico de drogas apresenta tendência inversa. É interessante notar a baixa responsabilização dos homicídios decorrentes de confronto policial, já que apenas um dos cinco casos analisados logrou condenação ao final, reforçando as constatações de outras pesquisas sobre o tema (BRINKS, 2007).

Tabela 4 - Distribuição dos tipos de homicídio, de acordo com a fase do fluxo de processamento - processos de homicídio doloso baixados em Belo Horizonte em 2013

\begin{tabular}{|c|c|c|c|c|c|c|}
\hline \multirow{2}{*}{ Tipo } & \multicolumn{2}{|c|}{ Denúncia } & \multicolumn{2}{|c|}{ Pronúncia } & \multicolumn{2}{|c|}{ Condenação } \\
\hline & N. & $\%$ & N. & $\%$ & N. & $\%$ \\
\hline Disputas relacionadas a casos amorosos (incluindo ex-parceiros) & 35 & $17 \%$ & 24 & $16 \%$ & 6 & $15 \%$ \\
\hline Briga entre familiares & 13 & $6 \%$ & 11 & $7 \%$ & 5 & $12 \%$ \\
\hline Briga entre conhecidos/vizinhos & 53 & $26 \%$ & 45 & $30 \%$ & 16 & $39 \%$ \\
\hline Briga entre desconhecidos & 24 & $12 \%$ & 22 & $15 \%$ & 5 & $12 \%$ \\
\hline Ação de gangues & 7 & $3 \%$ & 2 & $1 \%$ & 0 & $0 \%$ \\
\hline Tráfico de drogas & 38 & $19 \%$ & 20 & $13 \%$ & 4 & $10 \%$ \\
\hline Roubo (latrocínio) & 3 & $1 \%$ & 3 & $2 \%$ & 0 & $0 \%$ \\
\hline Cobrança de dívidas & 8 & $4 \%$ & 7 & $5 \%$ & 2 & $5 \%$ \\
\hline Confronto policial & 5 & $2 \%$ & 4 & $3 \%$ & 1 & $2 \%$ \\
\hline Vingança & 13 & $6 \%$ & 8 & $5 \%$ & 1 & $2 \%$ \\
\hline Outros & 6 & $3 \%$ & 5 & $3 \%$ & 1 & $2 \%$ \\
\hline Total & 205 & $100 \%$ & 151 & $100 \%$ & 41 & $100 \%$ \\
\hline
\end{tabular}

Fonte: Mensurando o tempo do processo de homicídio em cinco capitais (CRISP/ UFMG) 
Esse resultado pode ser explicado pela facilidade de coleta de provas em casos de delitos de proximidade (VASCONCELLOS, 2014), ao contrário do fraco conjunto probatório, que se dissolve ao longo do tempo, em casos de morte decorrente de dinâmicas criminosas, especialmente no tráfico de drogas, uma modalidade de crime em que os envolvidos tendem a ser eliminados por homicídios retaliatórios. Na próxima seção, procuraremos compreender como essas dinâmicas podem contribuir para a extensão ou redução do tempo de processamento.

\section{Factoides em busca de explicação para a variação nos tempos de processamento}

Em um texto publicado em 1969, Gresham M. Sykes chama a atenção para a necessidade de se examinar a lei em operação, notadamente, quando se trata de compreender as estratégias de administração do congestionamento ou excesso de demandas levadas ao sistema de justiça. Para o autor, era evidente que a demora dos processos não era igualmente distribuída, sendo mais pronunciada em casos carentes de visibilidade, em que o atraso no desfecho não produziria consequências políticas.

A construção do tempo de processamento como uma questão sociológica remonta à própria definição do significado de atraso (delay). Para Sykes (1969), a contagem do número de dias que transcorre entre o conhecimento do crime e o seu julgamento final não é suficiente para configurar a morosidade, em razão de essa qualificação só poder ser empregada quando existe "algum tempo desnecessário além do montante normal ou razoável" (SYKES, 1969: 329). Assim, a controvérsia reside na definição de qual seria o tempo necessário para cada caso em apreciação pelas cortes. Em outras palavras, "o problema é que não existe nenhum ponto crítico socialmente definido, que estabeleça o nível de morosidade a partir do qual uma determinada ação deve ser realizada" (Idem, ibidem).

O Código de Processo Penal (CPP) estabelece como prazo razoável o tempo de 315 dias para réu preso e 345 dias para réu solto. Esse poderia ser tomado como o prazo de duração razoável do processo, o qual, contudo, raramente é respeitado. De acordo com a Tabela 5 , existem casos que são muito rápidos, sendo encerrados em seis meses (valor mínimo), enquanto outros tardam quarenta anos (valor máximo) e, por isso, quando chegam ao julgamento já não são capazes de produzir efeitos socialmente relevantes, em razão da prescrição da punibilidade. Em média, são necessários dez anos para que uma morte violenta encontre uma resposta institucional na cidade de Belo Horizonte, sendo que os maiores gargalos se concentram nas fases judiciais, em especial, entre o recebimento da denúncia e a sentença da AIJ (quando ocorre a pronúncia) e entre a 
pronúncia e a sentença do júri. Em resumo, é difícil dizer o que constitui uma medida razoável de duração do processo penal de homicídio doloso considerando as medidas de tempo apresentadas na Tabela 5.

Tabela 5 - Estatísticas descritivas (em dias) do tempo de processamento das mortes violentas intencionais em Belo Horizonte, por fase - processos de homicídio doloso baixados em Belo Horizonte em 2013

\begin{tabular}{|l|c|c|c|c|c|c|}
\hline \multicolumn{2}{|c|}{ Fases } & \multicolumn{5}{c|}{ Estatísticas } \\
\cline { 2 - 7 } & Mínimo & Máximo & Média & Mediana & $\begin{array}{c}\text { Desvio } \\
\text { Padrão }\end{array}$ & $\begin{array}{c}\text { Casos } \\
\text { válidos }\end{array}$ \\
\hline $\begin{array}{l}\text { Tempo entre a data do crime } \\
\text { e a abertura do IP }\end{array}$ & 0 & 374 & 22 & 3 & 58 & 201 \\
\hline $\begin{array}{l}\text { Tempo entre a abertura } \\
\text { e o encerramento do IP }\end{array}$ & 0 & 4053 & 700 & 231 & 1025 & 184 \\
\hline $\begin{array}{l}\text { Tempo entre o encerramento do IP } \\
\text { e o oferecimento da denúncia }\end{array}$ & 0 & 2164 & 103 & 24 & 293 & 179 \\
\hline $\begin{array}{l}\text { Tempo entre o oferecimento } \\
\text { e o recebimento da denúncia }\end{array}$ & 0 & 7313 & 82 & 7 & 603 & 202 \\
\hline $\begin{array}{l}\text { Tempo entre o recebimento da } \\
\text { denúncia e a sentença da AIJ }\end{array}$ & 40 & 13598 & 786 & 583 & 1221 & 192 \\
\hline $\begin{array}{l}\text { Tempo entre a sentença da AIJ } \\
\text { e o julgamento pelo júri }\end{array}$ & 12 & 9889 & 1772 & 1225 & 1764 & 121 \\
\hline $\begin{array}{l}\text { Tempo final (considerando o tempo } \\
\text { de cada caso até onde ele sobreviveu) }\end{array}$ & 189 & 14688 & 3634 & 2961 & 2988 & 205 \\
\hline \begin{tabular}{l} 
Tempo final (em anos) \\
\hline
\end{tabular} & 0,5 & 40 & 10 & 8 & 8 & 205 \\
\hline
\end{tabular}

Fonte: Mensurando o tempo do processo de homicídio em cinco capitais (CRISP/ UFMG)

Em sua pesquisa sobre o tema, Sykes (1969: 333) limita-se a afirmar que o cálculo do tempo per si permite vislumbrar tão somente como as cortes carecem de uma estrutura burocrática, no sentido weberiano do termo, posto que a duração dos processos é sempre maior do que a esperada. Avançar sociologicamente na compreensão do fenômeno significa entender o tempo como o resultado dos grupos em disputa no âmbito de um tribunal.

Em regra, os indivíduos envolvidos no lento curso da justiça tendem a ser heterogêneos: alguns são oriundos das classes mais elevadas e podem arcar com um advogado, enquanto outros são jovens negros de periferia e têm contato com o defensor somente no momento da audiência. Contudo, os operadores do sistema são semelhantes em termos de origem social, formação e percepção de quais são os casos prioritários (ALMEIDA, 2014). Como as cortes se organizam 
com base em princípios burocráticos, que impõem linhas claras de autoridade, procedimentos padronizados para apreciação dos delitos e objetivos comuns em termos de desempenho (SYKES, 1969: 332), tem-se por hipótese que os operadores tendem a categorizar os casos a serem processados para aumentar a eficiência de seu trabalho. Partindo de critérios como (i) quem são os envolvidos, (ii) razões apontadas para a ocorrência da morte e (iii) grau de relacionamento entre autor e vítima, esses atores classificariam os casos a serem processados, dando-lhes um desfecho semelhante.

Seguindo essa linha de raciocínio, é de se esperar que o tempo de processamento varie de acordo com o tipo de homicídio, dada a tendência dos operadores de tratar casos semelhantes de maneira equivalente. Para testar essa hipótese, desagregamos o tempo final dos processos, considerando até onde cada caso sobreviveu (se pronúncia, se júri etc.), segundo as classes de homicídio intencional criadas neste trabalho. Adotando a mediana como baliza da duração, já que essa medida não é alterada por valores muito altos ou muito baixos de tempo, constatamos variações estatisticamente significativas no tempo de processamento dependendo do caso em questão (Tabela 6).

Tabela 6 - Estatísticas descritivas (em anos) do tempo final de processamento das mortes violentas intencionais em Belo Horizonte, por tipo de morte violenta - processos de homicídio doloso baixados em Belo Horizonte em 2013

\begin{tabular}{|l|c|c|c|c|c|c|}
\hline \multirow{2}{*}{ Tipologia } & \multicolumn{5}{|c|}{ Estatísticas } \\
\cline { 2 - 7 } & Mínimo & Máximo & Média & Mediana & $\begin{array}{c}\text { Desvio } \\
\text { Padrão }\end{array}$ & $\begin{array}{c}\text { Casos } \\
\text { válidos }\end{array}$ \\
\hline $\begin{array}{l}\text { Disputas relacionadas a casos amo- } \\
\text { rosos (incluindo ex-parceiros) }\end{array}$ & 0,7 & 31,5 & 9,3 & 7,8 & 7,1 & 35 \\
\hline Briga entre familiares & 1,6 & 28,4 & 8,2 & 4,3 & 8,5 & 13 \\
\hline Briga entre conhecidos/vizinhos & 0,7 & 40,2 & 11,8 & 9,7 & 9,6 & 53 \\
\hline Briga entre desconhecidos & 0,6 & 39,5 & 13,4 & 7,0 & 11,5 & 24 \\
\hline Ação de gangues & 2,1 & 11,8 & 6,6 & 5,5 & 3,6 & 7 \\
\hline Tráfico de drogas & 0,5 & 23,6 & 7,3 & 7,0 & 5,3 & 38 \\
\hline Roubo (latrocínio) & 8,9 & 26,5 & 16,1 & 12,8 & 9,2 & 3 \\
\hline Cobrança de dívidas & 2,7 & 14,1 & 7,1 & 6,6 & 4,0 & 8 \\
\hline Confronto policial & 3,8 & 17,0 & 9,8 & 10,1 & 4,8 & 5 \\
\hline Vingança & 2,4 & 25,8 & 11,2 & 10,5 & 6,3 & 13 \\
\hline Outros & 2,4 & 14,8 & 6,5 & 4,4 & 4,8 & 6 \\
\hline Total & 0,5 & 40,2 & 10,0 & 8,1 & 8,2 & 205 \\
\hline
\end{tabular}

$$
\mathrm{F}=3,75(0,021)
$$

Fonte: Mensurando o tempo do processo de homicídio em cinco capitais (CRISP/ UFMG) 
Em Belo Horizonte, o processo com menor duração foi o referente a uma morte relacionada a tráfico de drogas, que se encerrou em menos de seis meses. O mais lento foi o homicídio resultante de uma briga entre vizinhos, com 40,2 anos. $\mathrm{O}$ tempo médio de processamento foi de 10 anos, o que equivale quase à média de duração de um processo que envolve mortes decorrentes de confronto policial. Quando se observa a mediana de tempo, tomando-a como estatística de comparação dos casos, constata-se que os óbitos decorrentes de brigas entre familiares são os que experimentam menor morosidade, sendo encerrados em 4,3 anos, enquanto os decorrentes de latrocínio têm maior atraso no processamento completo, alcançando a marca de 9,2 anos.

Todavia, nem todos os casos analisados alcançaram a fase do júri, o que faz com que alguns processos tenham tempo muito pequeno (por terem se encerrado nas etapas iniciais do fluxo), enquanto outros contam com tempos muito elevados, alterando artificialmente as medidas de tendência central. Para contornar esse problema, Vargas (2004) entende que o cálculo do tempo global de processamento deve ser realizado a partir do emprego da técnica de análise de sobrevivência. Esse método estima funções de sobrevivência para cada caso, considerando a fase em que a maioria dos procedimentos termina, do ponto de vista temporal. A vantagem da função de sobrevivência é a estimativa do tempo, dependendo de quais são as chances de o processo sobreviver. É como se os casos tivessem pesos diferenciados, dependendo da fase em que foram encerrados (se no júri ou antes dele), o que contribui para que as médias e medianas sejam maiores do que as estimadas pelas medidas de tendência central. A forma de fazer essas estimativas é a partir do uso do Kaplan-Meier, dado que:

Ele utiliza conceitos de independência de eventos e de probabilidade condicional para desdobrar a condição de sobreviver até o tempo t em uma sequência de elementos independentes que caracterizam a sobrevida em cada intervalo de tempo anterior a t, cuja probabilidade é condicional aos que estão em risco em cada fase. A expressão estimador produto refere-se ao fato de que a ocorrência dos eventos são independentes e consequentemente a função de sobrevida é estimada utilizando o produto das probabilidades de sobrevida até o tempo t (CARVALHO et al., 2005: 102).

De acordo com Goel, Khanna e Kishore (2010), a curva de sobrevivência de Kaplan-Meier assume que, em princípio, todos os casos que estão censurados (aqueles que não sobrevivem até o final) têm as mesmas perspectivas de sobrevivência dos demais (que continuam no fluxo de processamento até o final). Em termos de procedimentos matemáticos, primeiro são estimadas as probabilidades de sobrevivência para casos que foram inseridos no início e no final do fluxo, 
ou seja, crimes ocorridos há vinte anos e crimes ocorridos em 2012, ano anterior ao recorte da pesquisa. Em seguida, são estimados os valores médios e medianos de tempo, considerando o tempo que o caso sobreviveu e as sobrevivências dos outros casos que alcançaram as fases finais do fluxo.

A estimativa de Kaplan-Meier é chamada de "limite estimativa produto" por se tratar do cômputo das probabilidades de ocorrência de eventos em determinado ponto do tempo e multiplicar essas probabilidades sucessivamente até obter a estimativa final (CARVALHO et al, 2005). A probabilidade de sobrevivência, em qualquer tempo particular, é calculada pela seguinte fórmula:

Fórmula 1 - probabilidade de sobrevivência

$$
\widehat{\operatorname{Var}}(\bar{S}(t))=\bar{S}(t)^{2} \sum_{t_{i} \leq t} \frac{d_{i}}{n_{i}\left(n_{i}-d_{i}\right)} .
$$

Fonte: Goel, Khanna e Kishore (2010: 2)

No começo da estimativa de Kaplan-Meier há a diferenciação dos eventos completos (aqueles que alcançaram a fase do júri) daqueles censurados (aqueles que se encerraram em fases, como a pronúncia). Como apresentado na Tabela 7 , os homicídios dolosos com mais filtragens ao longo do fluxo de processamento são os relativos aos conflitos amorosos (40\%) e tráfico de drogas (42,1\%). Por outro lado, todos os casos de óbitos que tiveram como causa cobrança de dívida ou confronto com a polícia foram levados a júri. Em suma, dependendo do tipo de morte violenta, existem chances diferenciadas de se alcançar (ou não) o julgamento.

Tabela 7 - Descrição da forma de classificação dos casos existentes na base de dados, para a análise de sobrevivência - processos de homicídio doloso baixados em Belo Horizonte em 2013

\begin{tabular}{lcccc}
\hline \multirow{2}{*}{ Tipologia } & \multicolumn{4}{c}{ Casos } \\
\cline { 2 - 5 } & Inicial & $\begin{array}{c}\text { Sobreviveram } \\
\text { até o Júri }\end{array}$ & $\begin{array}{c}\text { Morreram } \\
\text { antes do júri }\end{array}$ & $\begin{array}{c}\text { Percentual } \\
\text { de censuras }\end{array}$ \\
\hline $\begin{array}{l}\text { Disputas relacionadas a casos amo- } \\
\text { rosos (incluindo ex-parceiros) }\end{array}$ & 35 & 21 & 14 & $40,0 \%$ \\
Briga entre familiares & 13 & 10 & 3 & $23,1 \%$ \\
Briga entre conhecidos/vizinhos & 53 & 46 & 7 & $13,2 \%$ \\
Briga entre desconhecidos & 24 & 18 & 6 & $25,0 \%$ \\
Ação de gangues & 7 & 5 & 2 & $28,6 \%$ \\
Tráfico de drogas & 38 & 22 & 16 & $42,1 \%$ \\
Roubo (latrocínio) & 3 & 2 & 1 & $33,3 \%$ \\
Cobrança de dívidas & 8 & 8 & 0 & $0,0 \%$ \\
& & & & (continua)
\end{tabular}


(continuação)

\begin{tabular}{lcccc} 
Confronto policial & 5 & 5 & 0 & $0,0 \%$ \\
Vingança & 13 & 10 & 3 & $23,1 \%$ \\
Outros & 6 & 4 & 2 & $33,3 \%$ \\
Total & 205 & 151 & 54 & $26,3 \%$ \\
\hline
\end{tabular}

Fonte: Mensurando o tempo do processo de homicídio em cinco capitais (CRISP/ UFMG)

Após a diferenciação dos dados com censuras (lapso entre a data do crime e a data até a qual o caso sobreviveu) dos sem censuras (tempo entre a data do crime e o trânsito em julgado da sentença do júri) para cada tipo de homicídio, foram estimadas médias e medianas de tempo, que levaram em consideração a tramitação de todos esses crimes e criminosos, nas diversas agências que compõem o sistema de segurança pública e justiça criminal (Tabela 8).

Tabela 8 - Média e mediana do tempo (em anos) de processamento global, estimadas a partir do uso de Kaplan-Meier, por tipo de homicídio doloso - processos de homicídio doloso baixados em Belo Horizonte em 2013

\begin{tabular}{|c|c|c|c|c|c|c|c|c|}
\hline \multirow[b]{3}{*}{ Tipologia } & \multicolumn{4}{|c|}{ Média } & \multicolumn{4}{|c|}{ Mediana } \\
\hline & \multirow[b]{2}{*}{ Estimativa } & \multirow[b]{2}{*}{$\begin{array}{l}\text { Desvio } \\
\text { Padrão }\end{array}$} & \multicolumn{2}{|c|}{$\begin{array}{l}95 \% \text { Intervalo } \\
\text { de confiança }\end{array}$} & \multirow[b]{2}{*}{ Estimativa } & \multirow[b]{2}{*}{$\begin{array}{l}\text { Desvio } \\
\text { Padrão }\end{array}$} & \multicolumn{2}{|c|}{$\begin{array}{l}95 \% \text { Intervalo } \\
\text { de confiança }\end{array}$} \\
\hline & & & $\begin{array}{l}\text { Limite } \\
\text { Inferior }\end{array}$ & $\begin{array}{l}\text { Limite } \\
\text { superior }\end{array}$ & & & $\begin{array}{l}\text { Limite } \\
\text { inferior }\end{array}$ & $\begin{array}{l}\text { Limite } \\
\text { superior }\end{array}$ \\
\hline $\begin{array}{l}\text { Disputas relacionadas } \\
\text { a casos amorosos } \\
\text { (incluindo ex-parceiros) }\end{array}$ & 13,2 & 1,7 & 9,8 & 16,6 & 12,0 & 3,1 & 5,9 & 18,2 \\
\hline Briga entre familiares & 10,1 & 2,8 & 4,6 & 15,7 & 6,1 & 2,6 & 1,0 & 11,2 \\
\hline $\begin{array}{l}\text { Briga entre } \\
\text { conhecidos/vizinhos }\end{array}$ & 13,2 & 1,5 & 10,3 & 16,1 & 10,7 & 0,8 & 9,1 & 12,3 \\
\hline Briga entre desconhecidos & 16,5 & 3,0 & 10,6 & 22,5 & 12,6 & 4,3 & 4,2 & 21,0 \\
\hline Ação de gangues & 7,1 & 1,4 & 4,3 & 9,8 & 5,8 & 0,5 & 4,8 & 6,8 \\
\hline Tráfico de drogas & 10,8 & 1,6 & 7,8 & 13,9 & 9,2 & 2,1 & 5,1 & 13,3 \\
\hline Roubo (latrocínio) & 20,6 & 6,8 & 7,4 & 33,9 & 26,5 & 0,0 & . & . \\
\hline Cobrança de dívidas & 7,1 & 1,4 & 4,4 & 9,9 & 5,4 & 2,3 & 0,8 & 9,9 \\
\hline Confronto policial & 9,8 & 2,2 & 5,5 & 14,0 & 10,1 & 2,7 & 4,8 & 15,5 \\
\hline Vingança & 12,4 & 1,8 & 8,8 & 15,9 & 10,5 & 2,6 & 5,4 & 15,6 \\
\hline Outros & 7,6 & 2,1 & 3,5 & 11,7 & 3,5 & 2,9 & 0,0 & 9,2 \\
\hline Total & 12,8 & 0,8 & 11,1 & 14,4 & 10,2 & 0,8 & 8,6 & 11,8 \\
\hline
\end{tabular}

Fonte: Mensurando o tempo do processo de homicídio em cinco capitais (CRISP/ UFMG)

Os valores estimados pelo Kaplan-Meier são maiores que os apresentados anteriormente (Tabela 6) porque levam em consideração os casos que foram encerrados antes da sentença do júri, além da distribuição de pesos diferenciais para os processos que completaram todas as fases de processamento em relação 
aos demais. De acordo com a estimativa Kaplan-Meier, a mediana de tempo de processamento dos homicídios dolosos baixados em 2013, em Belo Horizonte, é de 10,2 anos (em vez de 8,1 anos). Agora, os casos mais rápidos são os enquadrados em "Outros", que demoram 3,5 anos para alcançar um desfecho (qualquer que seja ele). Os menores atrasos estão registrados nas mortes violentas decorrentes de cobrança de dívidas e ações entre gangues, cujos processos duram entre cinco e seis anos para se encerrarem. A maior demora é observada nos latrocínios, que levam mais de duas décadas para serem encerrados.

O Kaplan-Meier gera ainda uma curva de sobrevivência, que dispõe os valores individuais de tempo de cada caso e marca com uma cruz aqueles processos penais que foram encerrados antes da sentença do júri (censuras), além da fase temporal em que estão concentrados os encerramentos do procedimento que não chegaram até o júri. Ao comparar a duração do processo penal de acordo com os tipos de homicídio doloso (Gráfico 2), percebe-se que as censuras se distribuem ao longo de todo o tempo, com elevada concentração nos primeiros intervalos, o que pode sinalizar que, se o indiciado não for processado rapidamente, seu procedimento não sobreviverá até o júri.

Gráfico 2 - Tempo estimado a partir do Kaplan-Meier em curvas de sobrevivência, que indicam os pontos de tempo das censuras, por tipo de homicídio doloso - processos de homicídio doloso baixados em Belo Horizonte em 2013

\section{Survival Functions}

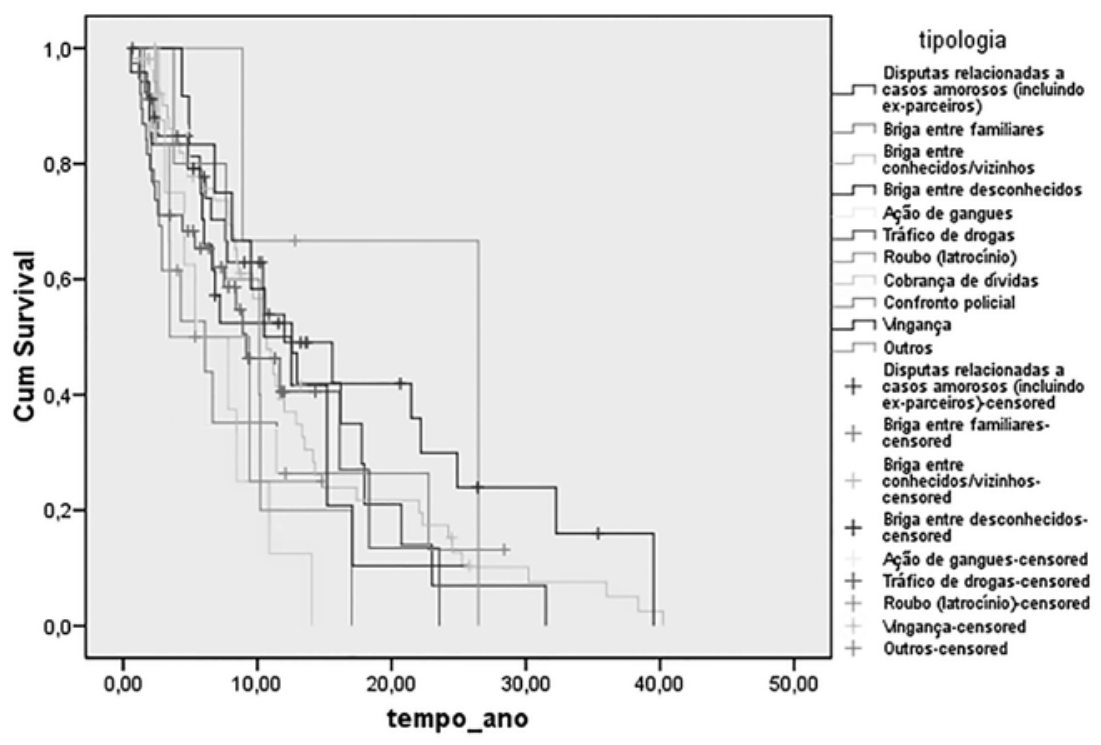

Fonte: Mensurando o tempo do processo de homicídio em cinco capitais (CRISP/ UFMG) 
Outra informação apresentada pelas curvas de análise de sobrevivência é a existência de um grande quantitativo de casos cuja duração do processo ultrapassa os 20 anos. De acordo com a legislação processual vigente no Brasil, os procedimentos que ultrapassarem o marco de 20 anos, perdem o seu valor e, com isso, é como se o processo deixasse de existir, já que ele não produz efeitos válidos; é o que se denomina prescrição. Esse instituto é problemático por transformar toda a preparação para o júri em algo inútil, pois, ao final, o réu deve ser liberado, em razão do excesso de tempo, não recebendo qualquer punição efetiva. Por outro lado, a prescrição pode ser entendida como uma medida de (in)justiça, posto que o réu suportou um processo penal por 20 anos, não conseguiu ser levado a julgamento e, dessa forma, não pôde provar a sua inocência (se for o caso) ou se ver livre da permanente acusação social de que o Estado não o puniu adequadamente.

A prescrição ocorreu em 31 dos 151 casos submetidos a julgamento pelo júri. Ela não alcançou as mortes que envolviam brigas entre familiares, ação de gangues e cobrança de dívidas, mas foi muito comum nos homicídios decorrentes de brigas entre conhecidos ou vizinhos ( 16 casos) e em um quantitativo substantivo de óbitos relacionados ao tráfico de drogas e casos amorosos (Tabela 9).

Tabela 9 - Distribuição dos casos de prescrição entre os processos analisados, por tipo de homicídio doloso - processos de homicídio doloso baixados em Belo Horizonte em 2013

\begin{tabular}{llccc}
\hline & & Houve prescrição do caso? & Total \\
\hline \multirow{2}{*}{ Tipologia } & Sim & Não & Sim \\
\cline { 2 - 4 } & $\begin{array}{l}\text { Disputas relacionadas a casos } \\
\text { amorosos (incluindo ex-parceiros) }\end{array}$ & 4 & 17 & 21 \\
& Briga entre familiares & 0 & 10 & 10 \\
& Briga entre conhecidos/vizinhos & 16 & 30 & 46 \\
& Briga entre desconhecidos & 1 & 17 & 18 \\
& Ação de gangues & 0 & 5 & 5 \\
& Tráfico de drogas & 4 & 18 & 22 \\
& Roubo (latrocínio) & 1 & 1 & 2 \\
& Cobrança de dívidas & 0 & 8 & 8 \\
Confronto policial & 1 & 4 & 5 \\
& Vingança & 2 & 8 & 10 \\
& Outros & 2 & 2 & 4 \\
& & 31 & 120 & 151 \\
\hline
\end{tabular}

Qui-quadrado $=17,67(0,035)$

Fonte: Mensurando o tempo do processo de homicídio em cinco capitais (CRISP/ UFMG) 
Os dados apresentados indicam que a morosidade pode ser uma função do tipo de delito em questão, que reúne em sua qualificação o perfil dos envolvidos, os "motivos" do crime e o grau de relacionamento entre autor e réu. Processos que examinam mortes violentas decorrentes de brigas entre familiares, ações de gangues e cobrança de dívida tendem a ser mais rápidos (de acordo com a mediana de tempo dada pela análise de sobrevivência) e menos susceptíveis a um processamento cuja sentença não possa produzir efeito em função da prescrição. Já casos relacionados a disputas amorosas e tráfico de drogas não apenas são mais susceptíveis à morosidade, como também são mais tendentes a serem interrompidos pela prescrição.

Os resultados encontrados reforçam o entendimento de Sykes (1969: 334) de que é possível prever a duração do processo a partir das características do delito de que se é acusado. A existência de diferenças temporais em função da tipologia de homicídios dolosos reforça o entendimento de que a justiça criminal funciona como um sistema em linha de montagem (SAPORI, 1995), em que casos semelhantes tendem a ter o mesmo padrão de seleção e filtragem e, por conseguinte, os mesmos atrasos.

Sykes (1969: 335) chama a atenção para como a duração do processo não pode ser menos relevante do que o resultado final (condenação ou absolvição), uma vez que o tempo ordena os casos, ao organizá-los de acordo com a disposição das cortes de apreciar determinados problemas. Um exemplo deste fenômeno talvez seja a morte violenta decorrente de casos amorosos, categoria que conta com um número expressivo de extinção da punibilidade por prescrição, 0 que termina por significar a não punição do acusado.

\section{Considerações finais}

A proposta deste artigo foi verificar se o tempo de processamento e o desfecho do processo penal tendem a ser distintos de acordo com o tipo de morte violenta. Com isso, pretendia-se assinalar a relevância de uma teoria que explique por que tipos diferentes de mortes violentas têm processos penais com duração e sentença final diferenciada. Para tanto, a discussão foi organizada a partir de dois marcos principais.

Na primeira seção, a tipologia das mortes violentas, que propõe um maior detalhamento das causas do óbito para melhoria no entendimento de suas dinâmicas de responsabilização, foi apresentada. Como o recorte deste trabalho é o de casos que foram levados a conhecimento das cortes belo-horizontinas e cujo exame se encerrou em 2013, o segundo marco foi a descrição dos procedimentos 
empregados pelos atores do sistema de segurança pública e justiça criminal para análise dos homicídios dolosos.

A terceira seção concatenou essas duas dimensões - tipologia de homicídios intencionais e funcionamento do sistema de segurança pública e justiça criminal - a partir da apresentação dos padrões de filtragem e do tempo de processamento. É claro que a medida pura e simples da duração do processo apresenta um cenário de morosidade bastante acentuada, posto que poucos são os casos que se encerram com um ano de duração, que seria, segundo os procedimentos previstos pelo CPP, um tempo próximo do razoável.

Partindo dessa moldura, se procurou verificar a relação entre a morosidade seletiva e como se dá a administração da justiça. A existência de padrões de seleção e filtragem diferenciados de acordo com o tipo de homicídio se explicaria, segundo as pesquisas existentes nesta área, em razão da cultura de que alguns casos merecem ser punidos, enquanto outros não merecem atenção, sendo esses os que ficariam mais susceptíveis à prescrição (CORRÊA, 1983; FAUSTO, 1984). A seletividade seria viabilizada pelos operadores do sistema de justiça criminal a partir da classificação dos casos, que garantiria o funcionamento do processo como uma matéria-prima dentro de uma linha de montagem (SAPORI, 1995). Neste diapasão, priorizar os casos relacionados a atividades criminosas parece ser racional em uma sociedade que justifica as suas mortes violentas como decorrentes do tráfico de drogas (SAPORI et al, 2010).

Os cruzamentos apresentados pelas tabelas dispostas no texto indicam a inexistência de um padrão decisório diferenciado de acordo com o tipo de morte violenta e, simultaneamente, a existência de durações diferenciadas de acordo com a classe dos homicídios intencionais. A seletividade parece estar associada à duração do processo, mais do que a decisão do juiz (na Audiência de Instrução e Julgamento) ou do Conselho de Sentença (na Audiência do Júri). A justiça em linha de montagem se verificaria muito mais na questão da velocidade, que significa a priorização de casos, como forma de se evitar a extinção da punibilidade pela prescrição. Todavia, mesmo mortes violentas relacionadas a atividades criminosas podem experimentar a morosidade se estiverem relacionadas, por exemplo, ao latrocínio, em detrimento da ação de gangues, que parece ser mais tendente a uma punição em um pequeno espaço de tempo.

A partir da técnica de análise de sobrevivência, constata-se que, dentro da categoria "homicídios intencionais", as mortes violentas que envolvem brigas entre familiares são processadas de maneira mais rápida do que disputas de afeto entre parceiros. Outro ponto de destaque é o número de conflitos entre conhecidos e vizinhos que se arrastam nos tribunais sem qualquer desfecho, 
sendo encerrados pela via da prescrição. Aparentemente, uma morte em contexto de proximidade resulta na desnecessidade de sua punição, fazendo com que esses processos terminem esquecidos.

Dentro da categoria "mortes relacionadas a atividades criminosas", a cobrança de dívidas teve processamento rápido, enquanto o tráfico de drogas experimentou morosidade, com casos levados a julgamento quase uma década após a sua ocorrência. No caso dos homicídios sociopolíticos, que são aqueles decorrentes de confronto policial, não houve seletividade, já que todos os casos foram levados a julgamento pelo júri, ainda que uma década depois do fato. Contudo, apenas um processo resultou em condenação, que não teve efeito em razão da prescrição, reforçando a dificuldade de se punir mortes praticadas pela polícia. Esse resultado reforça a ideia de que a seletividade não se dá pelo processo decisório (pronunciar ou não, condenar ou não), mas pela administração do tempo, que pode ensejar a extinção da punibilidade.

Portanto, o dilema da administração da justiça em Belo Horizonte significa que a liberdade para organizar quais casos devem ser processados de maneira prioritária termina por levar à constituição de determinadas dinâmicas de morosidade que são acionadas a partir da tipologia de mortes violentas dada pelas denúncias. Ao agirem dessa forma, os operadores terminam por confirmar a ideia de que somente as mortes com uma boa justificativa merecem apreciação pelo tribunal em menos de uma década (que é o tempo mediano de processamento), ainda que a decisão final seja a absolvição (o que ocorre em metade dos casos).

\section{Referências}

ALMEIDA, Frederico de. As elites da justiça: instituições, profissões e poder na política da justiça brasileira. Revista de Sociologia e Política, v. 22, n. 52, p. 77-95, 2014.

ADORNO, Sérgio. Prefácio. In: FAUSTO, Boris. Crime e cotidiano: a criminalidade em São Paulo (1880-1924). 2ª. Edição. São Paulo: EDUSP, 2001.

BERGER, Peter L.; LUCKMANN, Thomas. The social construction of reality: a treatise in the sociology of knowledge. London: Penguin UK, 1991.

BRINKS, Daniel M. The judicial response to police killings in Latin America: inequality and the rule of law. United Kingdom: Cambridge University Press, 2007.

CARVALHO, Marília Sá et al. Análise de sobrevida. Rio de Janeiro: Fiocruz, 2005. CORRÊA, Mariza. Morte em família: representações jurídicas de papéis sexuais. Rio de Janeiro: Graal, 1983. 
FAUSTO, Boris. Crime e cotidiano: a criminalidade em São Paulo (1880-1924). São Paulo: Edusp, 1984.

GOEL, Manish Kumar; KHANNA, Pardeep; KISHORE, Jugal. Understanding survival analysis: Kaplan-Meier estimate. International Journal of Ayurveda Research, Betheseda: v. 1, n. 4, p. 274, 2010.

MARTINS, José de Souza. Linchamentos: a justiça popular no Brasil. São Paulo: Contexto, 2015.

MISSE, Michel. Autos de resistência: uma análise dos homicídios cometidos por policiais na cidade do Rio de Janeiro (2001-2011). Relatório Final de Pesquisa-Núcleo de Estudos da Cidadania, Conflitos e Violência Urbana. Rio de Janeiro: Universidade Federal do Rio de Janeiro. Mimeo, 2011.

SAPORI, Luís Flávio. A administração da justiça criminal numa área metropolitana. Revista Brasileira de Ciências Sociais, São Paulo v. 10, n. 29, p. 143-157, 1995.

SAPORI, Luis Flavio; SENA, Lucia Lamounier; SILVA, B. Mercado do crack e violência urbana na cidade de Belo Horizonte. In: SAPORI, LF; MEDEIROS, R (Orgs.). Crack: um desafio social. Belo Horizonte: Ed. PUC Minas, 2010.

SILVA, Klarissa Almeida. O papel dos tipos de homicídios dolosos na construção social da incriminação dos sujeitos pelos promotores de justiça: Belo Horizonte, processos em andamento entre 2007 e 2009. Dilemas: Revista de Estudos de Conflito e Controle Social, Rio de Janeiro, v. 8, p. 101-123, 2010.

SILVA, Klarissa Almeida. A Construção Social e Institucional do Homicídio: da perícia em local de morte à sentença condenatória. Tese de doutorado, Sociologia, UFRJ, 2013. SOARES, Gláucio Ary Dillon. Homicídios no Brasil: vários factoides em busca de uma teoria. Relatório parcial do projeto Covariatas Macroestruturais do homicídio no Brasil. In: Meeting of the Latin American Studies Association. Miami: Latin American Studies Association, Hyatt Regency Miami. 2000. p. 10-24.

SUDNOW, David. La organización social de la muerte. Buenos Aires: Editorial Tiempo Contemporáneo, 1971.

SYKES, Gresham M. Cases, Courts, and Congestion. In: NADER, Laura. Law in Culture and Society. Chicago: Aldine, 1969. Pp. 327-336.

UNDOC. Study on Global Homicide 2013. Vienna: United Nations Office on Drugs and Crime (UNODC), 2014.

VARGAS, Joana Domingues. Estupro: que justiça? Fluxo do funcionamento e análise do tempo da justiça criminal para o crime de estupro. Tese de doutorado, Sociologia, IUPERJ, 2004.

VARGAS, Joana Domingues. Fluxo do sistema de justiça criminal. In: LIMA, Renato; RATTON, José Luiz; AZEVEDO, Rodrigo (Orgs.). Crime, segurança e justiça no Brasil. São Paulo: Contexto, 2014. 
VASCONCELLOS, Fernanda B. Delitos de proximidade e violência doméstica. In: LIMA, Renato Sérgio de; RATTON, José Luiz; AZEVEDO, Rodrigo Ghiringhelli de. (org.). Crime, polícia e justiça no Brasil. $1^{\mathrm{a}}$ ed. São Paulo: Editora Contexto, 2014, v. 1, p. 293-298.

Recebido em 20/08/2015

Aprovado em 07/05/ 2017

\section{Como citar este artigo:}

RIBEIRO, Ludmila Mendonça Lopes, COUTO, Vinícius Assis. Tipos de homicídio e formas de processamento: existe relação? Contemporânea - Revista de Sociologia da UFSCar, v. 7, n. 2, jul.- dez. 2017, pp. 417-442. 